\title{
Time Doesn't Heal All Wounds: A Call to End Mandated Reporting Laws
}

G INGUANTA, THEY/THEM CATHARINE SCIOLLA, SHE/HER

Mandated reporting laws are pertinent to practitioners of "helping professions," such as social workers, doctors, nurses, and teachers. These laws dictate that a professional or student in those fields must report suspected child maltreatment to the state for investigation. The report, as well as the investigation that follows, has the potential to result in removal and separation of children from their parents or caretakers. The child welfare system of which mandated reporting is a component has a cruel history of racism and white supremacy, as well as prejudice towards those experiencing poverty, disabilities, mental health concerns, homelessness, and substance use disorders. This research examines the disproportionate harm the child welfare system has on Black and Brown individuals, particularly in New York, and how the system has used mandated reporting laws to further marginalize oppressed communities since the 1970s. This research indicates the need to comprehensively reimagine the erroneously named "child welfare system" starting with repealing mandated reporting laws in the United States.

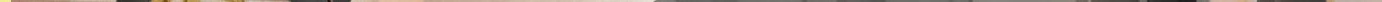




\section{TIME DOESN'T HEAL ALL WOUNDS: A CALL TO END MANDATED REPORTING LAWS}

\section{LITERATURE REVIEW}

THE FOUNDATIONS OF AMERICA'S MODERN FAMILY REGULATION SYSTEM

Historically, the "family regulation system," a term coined by Dorothy Roberts in 2020 for the industry more commonly known as the child welfare system ${ }^{1}$, dates back to the 1850 s, informally starting with what is known as the Orphan Train movement. Between 1854 and 1929, thousands of poor children from urban settings were kidnapped, ${ }^{2}$ and they were moved across the country to be housed with white, AngloSaxon protestant parents (Orphan Train, 2020). Even though the work of the Orphan Train movement was reformed through social welfare policy within the United States later on with legislation like the Child Abuse Prevention and Treatment Act (CAPTA), the destruction of families and removal of children from homes has long been a tradition in the United States. White saviorism ${ }^{3}$ and paternalism are the backbone of the family regulation system, whose foundational pillars also include the forced

1 In her 2020 article, Roberts connected the child welfare system and the criminal justice system as two pawns playing in the larger carceral regime. She elaborates upon this notion: "The misnamed 'child welfare' system, like the misnamed 'criminal justice' system, is designed to regulate and punish black and other marginalized people. It could be more accurately referred to as the 'family regulation system."” (Roberts, 2020).

2 The term kidnapped is not used as hyperbole. We believe this to be fact. When individuals move children across state lines it is considered kidnapping. Why then does this definition not apply to the actions of the state as well? The state has a simultaneous monopoly on both violence and the conceptualization of violence (Anter 2019). Children during the Orphan Train movement were taken out of their culture, families, and homes and shipped across the United States because one white man, Charles Loring Brace, thought it would be best for them. Oftentimes many children did not know or understand where they were being taken and in some cases were forced to end all contact with their birth families (Brown et al., 2020). To understand the impact the Orphan Train Movement had on children please visit: https://socialwelfare.library.vcu.edu/programs/childwelfarechild-labor/orphan-trains/

3 White Saviorism is a term used to describe white people who "help" Black people and people of color in a self-serving manner. White saviorism is most commonly associated with individual acts that perpetuate colonialism and imperialism, particularly in the African continent: volunteer tourism and missionary work, for example. Instead of allowing communities to make decisions for themselves, white people come in to "help" as a form of aid, perpetuating a dangerous narrative that white people must be centered in order for BIPOC oppression to end. sterilization of Black, Indigenous, People of Color (BIPOC) women and folks with disabilities, as well as eugenics (Sterilization and Social Justice Lab [SSJL]). This is the enduring legacy of our modern system: building blocks rooted in paternalism and white supremacy.

The mentality of the Orphan Train movement of the 1850s was to "clean up" the streets of cities and produce "upstanding" citizens, while doing nothing to end the conditions of poverty those children endured. This mentality affects how Americans think about and make laws regarding childhood, poverty, and what does or does not constitute abuse or neglect. In fact, the United States' obsession with the "safety" and "protection" of its children is thinly veiled and coded language used to justify its true and more insidious nature: to destroy the Black family (as well as Native American families, Brown families, and later immigrant families living in poverty).

Between 1929 and the 1960s, orphanages were replaced with foster care and programming to aid "poor children and families" (Forestdale, n.d.). However, it was not until the 1960 s that this mentality of "programming for the poor" and foster care became the framework of the modern day family regulation system and the "foster care industrial complex." The modern family regulation system was developing parallel to the United States government's assault on Black, Native American, Brown, and immigrant communities; in some instances, this assault was on low-income white folks as well.

Key to the development of the modern family regulation system is the narrative of the "battered child syndrome." In 1962, the term "Battered Child Syndrome" was created to describe the clinical condition of severely abused, neglected, or maltreated children which could result in death (Kempe et al., 1985). Three years after the publication naming "Battered Child Syndrome," all fifty states had passed legislation requiring doctors to report suspected child abuse or neglect (Melton, 2004). Originating from the concept of "Battered Child Syndrome," as defined by Kempe, mandated reporting initially focused on disseminating information to doctors about how to identify and properly report abuse 
to authorities. Kempe's research was narrowly focused on the most severe forms of abuse (e.g., broken bones), but he generalized his findings to create a universal standard for any child suspected of experiencing abuse. This generalization was not only quite a leap, but was also dangerous. The family regulation system has become a tool of surveillance, which has been weaponized against Black communities, communities of color, and communities living at or below the poverty line. Shortly thereafter, CAPTA was passed, which "provides Federal funding and guidance to States in support of prevention, assessment, investigation, prosecution, and treatment activities" (Child Welfare Information Gateway, 2019, p. 1).

Around the same time, a feeling of moral superiority was being promoted through the creation of the "war on drugs" by President Nixon in 1971. By 1980, President Reagan had widely expanded the criminalization of drug use, particularly crack-cocaine, and the prison industrial complex (DuVernay, 2016). Importantly, Nixon's “war on drugs" invented the racialized myth of the crack-addicted baby, a pervasive stereotype that looms over the family regulation system to this day (Wexler, 2019).

Mandated reporting laws were born out of a movement to "clean up" and rid city streets of "child gangs" (Brown et al., 2020) and a nationwide panic around severe abuse observed in a small percentage of children (Mandatory Reporting Study, 2020). Instead of addressing some of the contributing factors to child abuse like historical trauma, patriarchy, and white supremacy, mandated reporting laws were passed that individualized issues of poverty and domestic violence as a failure of an individual or a family, rather than a failure of society to address the mental and physical well-being of its citizens. This attitude of moral superiority, paternalism, and victim blaming is one that continues to frame the family regulation system and has historically been used as a tool of political and economic agendas in America, including the war on drugs.

In this paper we will review research and analyze the implications mandated reporting laws have had on Black families (as well as Native
American, Brown and immigrant families, including but not limited to all families who live at or below the poverty line $)^{4}$. We will recommend, based on our research and experiences serving in the legal and social service sector, to abolish the family regulation system by ending mandated reporting laws. We do not believe that ending the family regulation system and mandated reporting laws will put an end to all abuse, nor do we promote ignoring violence towards children. Though the family regulation system purports and falsely claims to be about protecting children, when observing the experiences and realities of folks ensnared in the family regulation system and looking at data, we have concluded that the family regulation system is the largest perpetrator of violence, abuse, and neglect to children and families. Our intention is to clarify and affirm the latter narrative in order to chip away at the legitimacy of institutions operating within the family regulation system and to take a critical look at mandated reporting as a tool of white supremacy.

For far too long, Black mothers and families have had to endure family separation while their voices were silenced by powerful and well-funded institutions. From our research on Black scholars and the voices of Black moms, we, as authors, have learned about the racial disproportionality of the current family regulation system. We must get rid of it and work towards creating a world where Black voices and families have self determination over their own futures. This includes understanding how the terms "abuse" and "neglect" have been weaponized against Black, Native American, Brown, immigrant, and low-income families. This means that we must slowly gut, defund, and transition away from our society's reliance on punitive institutions like the State Central Registry--the "centralized" database of all child abuse, maltreatment, and neglect cases-- and toward funding and handing over power to Black, Native American, Brown, and immigrant communities

4 Operationalized by Christina Bush, the theory of anti-Blackness postulates that systemic racism in America exists "through the denigration, disenfranchisement, and disavowal of people racialized as Black" (Bush, n.d.). That anti-Blackness permeates all aspects of society is evident when looking at systemically racist policies and practices, de-facto segregation, redlining, misogynoir, and police violence. 
and families. ${ }^{5} \mathrm{~A}$ first step towards this goal is to end mandated reporting.

\section{THE PURPOSEFUL AMBIGUITY OF MANDATED REPORTING AND ITS IMPACTS}

Mandated reporting is a relatively new concept for social workers, dating back less than 50 years to the inception of the Child Abuse Prevention and Treatment Act in 1974. In its short life, however, the principle of mandated reporting has done significantly more harm than good. As previously stated, mandated reporting came about as a result of Dr. Kempe's research on "Battered Child Syndrome (BCS)," and the fear that ensued regarding child maltreatment, abuse, and neglect. "BCS" should be diagnosed when there is a presence "...of fracture of any bone, subdural hematoma, failure to thrive, soft tissue swellings or skin bruising, in any child who dies suddenly, or where the degree and type of injury is at variance with the history given regarding the occurrence of the trauma" (Kempe et al., 1962). It is noteworthy that federal mandated reporting legislation rests on abuse that is only the most serious, though due to the ambiguity of mandated reporting laws and the legal consequences of not reporting, over-reporting as a precaution dilutes what is actually a case of serious abuse and what is not. This overreporting disportionately affects Black, Indigenous, and Latinx families. ${ }^{6}$

5 We would like to recognize that there are cases of severe and dire child abuse and neglect that, heartbreakingly, often go unstopped by governement entities, as interference only occurs when it is too late. Thus, we align with the same ideology as the upEND movement in that "we want to support the formation of communities and a society where harm does not occur in the first place and where harm does occur, communities are able to respond in ways that do not create more harm" (upEND, FAQs).

6 "In calendar year 2019, 41.4\% of New York Statewide Central Register of Child Abuse and Maltreatment reports involved children in families who identified as Black/African American, even though these children only make up about $23 \%$ of the NYC child population, and $45.4 \%$ of reports involved children in families who identified as Latinx/Hispanic, even though these children comprise $36.4 \%$ of the NYC child population. On the other hand, while $26.5 \%$ of NYC children are White and $14.1 \%$ of NYC children are Asian/Pacific Islander, these families make up $8 \%$ and $5.3 \%$ respectively of reports to the SCR" (Oversight-Racial Disparities in the Child Welfare System, 2020, p. 5).
Mandated reporters are often inconsistent about the reporting of suspected child abuse, neglect, and maltreatment, both because of the unclear guidelines set forth by national law and because of the incongruence between mandating reporting and professional ethics (Feng et al., 2012). The threshold for mandated reporters in New York State is "any reasonable suspicion." Many professionals disagree on what constitutes reasonable suspicion, at what point to report, and how to go about this conversation with clients. The New York State Office of Children and Family Services Summary Guide for Mandated Reporters (2019) defines reasonable suspicion as "a suspicion that the parent or other person legally responsible for a child is responsible for harming that child or placing that child in imminent danger of harm. Your suspicion can be as simple as distrusting an explanation for an injury" (2019, p.2).

Given the wide range of professions that fall under mandatory reporting laws- doctors, nurses, social workers, psychiatrists, teachersit is understandable that there is no consensus on how to interpret "reasonable suspicion." What that means to a doctor in a hospital setting is very different form what it means to a teacher in a kindergarten classroom, or a therapist in a counseling session. Specifically for medical professionals, evidence reveals that providers are more likely to report families and individuals of color even when presenting with the same injuries and demographic factors as white families and individuals (Hlavinka, 2021). This indicates that racial biases within the medical field are not limited to the care and compassion received by patients of color, but also extends to the trust and support they receive from their physicians and medical staff (Hlavinka, 2021).

Furthermore, research also suggests that even within professions there is no agreement on the threshold of reasonable suspicion, noting that this can vary from person to person, department to department, and specialty to specialty (Levi \& Crowell, 2011). This ambiguity is purposeful and creates an environment where racial bias thrives. This continues the destruction of Black, Native American, Brown, immigrant, and low income families. 
Mandated reporting and the possibility of a report being made diminishes the strength of the therapeutic alliance and the clinical benefits of work between clinicians and their clients (and trust between doctors and medical staff and their patients). Critics of mandated reporting have long argued that having clinicians as mandated reporters damages the work that clinicians can do by disrupting the therapeutic alliance. The potential of reporting may hinder the work that a clinician can do with a client, as the client may be monitoring and censoring what they say throughout sessions, causing a rupture in the therapeutic alliance and diminishing healing and growth as a result. Critics note that this is a major concern for clinicians who utilize a psychodynamic or psychotherapeutic approach (Kalichman, 1999). If a client discloses that harm is occurring, the clinician is in the position to successfully deliver an intervention and discuss the root causes of the abuse. To report, the clinician or professional must break confidentiality, which has harmful effects on the client-clinician relationship (Kalichman, 1999).

How do social work practitioners justify the harm done through the family regulation system's mandating a report report while striving to achieve their code of ethics? Can they? Due to the legal ramifications of not reporting, does the mandated reporting law actually coerce professionals into reporting to prevent legal recourse? Does this ultimately disproportionately favor reporting over not reporting at all?

\section{THE ARGUMENT TO KEEP FAMILIES TOGETHER}

Historically, the narrative of the family regulation system has been couched in language like "protecting children," thus erasing the voices of directly impacted individuals and promoting stories that fit the narrative of white saviorism. If the social problem is framed as poverty or individual failure, then the intervention is separating families to preserve the child's safety. However, research demonstrates that, in most cases, keeping a family together is best, and reporting can be harmful to families (Kalichman, 1999). Thompson and Flood (2002) argued that the best way to protect children is to emphasize preventive and support services that would help with family preservation and maintaining family ties, even when it is unsafe for children to live with their parents. Research also indicates there is a specific pattern of cases that are reported and re-reported. The characteristics of these cases include, but are not limited to, social support deficits, family stress, and partner abuse (DePanflis \& Zuravin, 2002). Families who fit this profile but use the services provided have been shown to be $33 \%$ less likely to have another report placed for them (DePanflis \& Zuravin, 2002). This indicates that identifying proper support services for families to participate in is effective in reducing re-reporting (DePanflis \& Zuravin, 2002). Given the main case characteristics, future considerations for increased support services should include aligning families with others to increase social support, psychoeducation around stress and abuse, and family violence intervention programs through a trauma-informed and culturally humble approach.

In addition to the pattern of report and re-report, there is also evidence for a high correlation between re-reporting and specific "risk" factors. Connell et al. (2006) found that family poverty was the strongest predictor of re-reporting. Other predictors of re-reporting include community poverty level, family history of substance abuse, and domestic violence. This strongly suggests a correlation between socioeconomic status, income level, mental health, and victimization--all of which are dictated by race in the U.S.--and re-reporting. These "risk factors" further reveal mandated reporting's continued legacy of oppression, systemic racism, and intergenerational trauma within the Black community (Hernández et al., 2005).

\section{MODERN DAY RACISM: EFFECTS OF MANDATED REPORTING}

It is evident that white supremacy is the ideological backbone of the family regulation system. Through the operation of the family regulation system, including the foster care system, the United States demonstrates that it believes the state will do a better job of parenting a child than those living in poverty, specifically Black folks, Indigenous individuals, immigrants, and people with disabilities. This is the intent of the family 
regulation system and has been since its formation; it is by choice, not coincidence, as was seen in the Orphan Train's movement to "clean up" urban communities. This kind of thinking has a dire legacy in the United States and must end.

Mandated reporting contributes to the racial disproportionality within the family regulation system at both state and federal levels. The first manuscript reporting racial disproportionality in the family regulation system dates back to 1972 (Billingsley \& Giovannoni, 1972), and its findings continue to hold true 45 years later. In 2000, it was reported that Black children represented $38 \%$ of the foster care system while being only $16 \%$ of the national population (National Council of Juvenile and Family Court Judges [NCJFCJ], 2017). Between the years of 2000 and 2011, Black children were twice as likely to be removed from their parents care as white children (Sangoi, 2020). Black children were overrepresented in foster care in 46 of the 50 states in 2015 (NCJFCJ, 2017). In 2015-2018, only 9 out of every 1,000 cases in the United States reported to child protective services were confirmed cases of maltreatment (KIDS Count, 2018). In 2017, in California and New York, Black children were represented three times more in foster care than they were in the state's population (NCJFCJ, 2017). Of cases that were confirmed as maltreatment, in 2018, 18\% involved Black families and $23 \%$ involved Hispanic or Latino families (KIDS Count, 2018). Thus, for 2018, children of color accounted for approximately $65 \%$ of all children in foster care throughout the United States (KIDS Count, 2018). As of 2020, children that are Black represent $23 \%$ of kids in the family regulation system while only representing $14 \%$ of the national population (KIDS Count, 2020).

While some states have universal reporting laws, others only require professional mandated reporters (Krase \& DeLong-Hamilton, 2015). More than half of the 3.3 million reports of child maltreatment in 2011 were carried out by these professionals (United States Department of Health and Human Services, Administration on Children, Youth, and Families, 2012).
Black families and caregivers are more likely to be reported for maltreatment than white families (Miller, 2008; Putnam-Hornstein et al., 2013). In New York State, Black families and caregivers are disproportionately reported for child maltreatment by school employees via mandated reporting (Krase, 2015). The ongoing surveillance and involvement with the family regulation system reinforces negative stereotypes of Black individuals and families, such as the lack of ability to take care of their children without government assistance (Dettlaff et al., 2020).

While the state claims to protect children, state intervention in family matters is insidious and has far-reaching consequences that further compound the trauma of living in a white supremacist society. Additionally, the narrative that family separation benefits both children and parents is an outright falsehood disproven by research that indicates the negative impacts it has on the wellbeing of children and families (Rethinking Foster Care, 2014). In addition to research that proves the long-lasting trauma families experience due to state intervention, there is also a robust amount of research that points to a clear pipeline between foster care and prison (Center, 2018).

As explained by Dorothy Roberts (2002), mandated reporting has reverberating effects at the local and personal levels. Communities consisting of Black families are plagued by mandated reporting, surveillance, and separation, thereby enduring harm to their individual and collective identities. Each of these makes it difficult for people and families of color to build stable bonds and overcome additional disadvantages. Roberts (2008) reported a lack of community involvement, as well as diminished social connection, lower quality friendships, and less supportive bonds due to fear of child welfare intervention by the state and fear of the possible calls and reports made by disgruntled neighbors as a result of other social conflicts.

As Black and other communities of color continuously suffer from racist systems and policies, their negative health outcomes and poor living conditions, caused by white supremacy and the cultural imperialism of 
America, are then used against them in the form of mandated reporting and state-led interventions like child removal. This perpetuates the historically traumatic narrative of Black families as unworthy or incapable.

\section{CURRENT PRACTICES OF HARM}

Mandatory reporting laws do not account for a reporter's own personal experiences, biases, or beliefs. There is a well-documented racial issue within the family regulation system, as discussed in the previous section. Historically, white, Anglo-Saxon, upper middle-class individuals have dictated what is appropriate, what is inappropriate, and what is "right" when it comes to parenting and family values. This notion of the "white lens" is clearly evident in the family regulation system where we see families punished for not meeting upper middle-class, AngloSaxon standards. ${ }^{7}$ It is clear that the immediate need of children and families dealing with the family regulation system is the abolition of the family regulation system. It should be replaced with the integration of community-based services that are preventative and promote child, family, and community wellbeing, as well as the acknowledgement of the race-based motivation behind the trauma inflicted on children, families, and communities of color under the guise of this system. We also believe that the family regulation system should be defunded and the money reinvested back into the community, with community members at the forefront of deciding what gets funded.

\section{CENTERING FAMILY SUCCESS}

The family regulation system is made up of two arms: the legal industry and the social service industry. The entire industry sits below the legal and prosecutorial infrastructure that is dependent upon family court and reporting for its economic survival (Rethinking Foster Care, 2014). Ultimately, do families need more services, where they will come into

$7 \mathrm{~A}$ recent example of this is the disproportionate number of marijuana-related reports on BIPOC folks in low socio-economic neighborhoods, and the heraliding of marijuana use as a form of selfcare for white and upper-class parents (Ketteringham, 2019). contact with even more mandated reporters? Or do researchers, activists, impacted parents, lawyers, and other advocates need to push towards abolishing the state intervention system all together, while fighting for social change that will put an end to racial trauma and disparities?

Between the years of 2015-2018, less than 1\% of cases reported to child protective services were substantiated, or found to be confirmed cases of maltreatment (KIDS Count, 2018). The most common finding nationwide in family court is one of neglect, not abuse (National Child Abuse Statistics from NCA, 2020). The charge of neglect is usually an indictment of the parent's ability to meet a child's needs due to poverty. The charge of neglect is how the family regulation system continuously punishes folks living at or below the poverty line, blaming them as an "individual failure," rather than systemic failure. Over and over research shows families involved in the family regulation system are most likely living at or below the federal poverty line (Joyce, 2019).

Reports show that the family regulation industrial complex spends tens of billions of dollars each year, with estimates citing that between 2004 and 2014 spending of state, local, and federal dollars reached up to 32 billion dollars each year (Sangoi, 2020). For scale, the state, local, and federal average annual spending on the Women, Infants, and Children Supplemental Nutrition Program, providing support and programs for children under three living in poverty, is 6 billion dollars (Sangoi, 2020, p. 131). Yet, with roughly five times as much being spent on the family regulation system, the dollars do not reach families and children in need of services and support; the vast majority of this spending was on "outof-home placement”: not keeping families together (Sangoi, 2020, p. 131).

The most appropriate use of resources for the family regulation system would be to develop services that "meet the needs of such families," and "to reduce the risk of recurrent allegations among families faced with economic challenges" (Connell et al., 2002, p. 584). In practice, this would mean prioritizing the voices of directly impacted individuals and communities by creating sustainable programs that are built around the demands of families involved in the family regulation 
system. Directly impacted individuals, families, and communities have argued for decades that decreasing surveillance and oppressive infrastructure operated through mandated reporting will lead to less childhood trauma, greater intra-community trust, disclosure amongst participants and care providers, and overall greater wellbeing (Roberts, 2002).

The state-mandated intervention systems have operated as a means through which to control, manipulate, and oppress communities of color and those living in poverty. It is time for change. Building community resources and services would innately involve directly impacted individuals, families, and communities, who are the experts in their own lives and needs, by asking, "what do you need?"

\section{A CALL FOR CHANGE: ABOLISH MANDATED REPORTING LAWS}

Not only have we imagined, based on the voices of Black folks who have worked as lawyers, scholars, and who have been impacted by the family regulation system, what a world without the family regulation system could look like, but we have also highlighted the harm that the current system does and the values that control the current decision making processes within the system. The "child welfare" system we currently have is not working to protect children and families, nor is it increasing child wellbeing. It is a system deeply rooted in oppression, surveillance, and punishment of BIPOC communities and brutally enforces a white, Anglo-Saxon style of parenting. How do we prevent children and families from experiencing trauma at the hands of the family regulation system? What is a successful first step in abolishing the family regulation system?

We narrowed our focus to abolishing mandated reporting laws, which was directly inspired by Joyce McMillan's call to end Mandated Reporting. Without mandated reporting laws, we believe that clients would disclose more openly and productively in clinical work, at the doctor, and with teachers. In doing so, folks can actually get the adequate mental and physical health care they need and deserve. For example, due to mandated reporting at public hospitals, many pregnant people will not go to prenatal appointments for fear of a report being filed against them, especially due to any positive toxicology report (Khan, 2019). Without mandated reporting, birthing folks would more likely attend all prenatal sessions, which could in turn decrease the mother and infant mortality rates of both Black and non-Black birthing folks. In sum, trust can be built up between client and provider in systems that are historically oppressive and punitive, and clients will be able to get more out of services, because services will actually deliver their intended impact and interventions. Children and families' wellbeing will flourish because only cases that have actual merit or need will be reported and the fear of stateimposed trauma this system instills will be removed.

A world without an added layer of surveillance from mandated reporting means a world where there will be: 1) increased child wellbeing in communities where the family regulation system's presence is high; 2) less undue trauma to youth and families; 3) greater intercommunities and intra-community trust; and 4) less violence overall. As social workers, we also recognize the potential for less burn out and more time to work intimately with clients and community members. In this world, we imagine there will be greater collaboration amongst organizations, community entities, neighbors, and schools. Without the fear of mandated reporting hindering access to care or trust in authority figures, greater fidelity to services can be provided, relationships between families and schools can improve, and medical well-visits can be regularly attended. In this world, we imagine self-determination for families and choices made with consent and knowledge rather than in fear. We imagine communities solving their own problems and service providers, like social workers, stepping in only if requested. Love and justice are at the core of our call to end mandated reporting laws.

The implications of this research suggest that change is needed at several levels, including the individual, family, community, state, and federal. We demand that advocates, social workers, and lawyers take the lead from those who have been most impacted: parents who have experienced the family regulation system and children whose lives have 
been turned upside down due to family separation. Our hope is that this paper can spark a conversation more broadly amongst providers, including those working within the family regulation system, social workers in schools and hospitals, medical staff, and people who are unaware of the serious harms the family regulation system commits everyday in the name of "child safety."

\section{RESEARCH LIMITATIONS}

The researchers are passionate about contributing to this growing body of knowledge, and we want our scholarship to be used to bolster the existing advocacy of impacted parents to amend or abolish the family regulation system. As folks who have not been directly harmed by this particular system, we only understand the mechanisms through scholarly work and working directly with those most impacted. Often, directly impacted individuals are not given the option to engage with or draw conclusions about the systemic issues behind the family regulation system, but are rather forced to do so. As white researchers and academics, we are a part of the systems of colonialism and white supremacy that continue to marginalize those most impacted by this issue. Academia is predominantly an institution and tool of white supremacy, often stealing from and profiting off of the ideas and struggles of BIPOC, immigrants, LGBT+ individuals, people with disabilities, and poor communities. It is our hope that this research can be used as a tool by those most impacted to advocate for themselves and their communities, and as a conversation starter for service providers and mandated reporters.

\section{DEDICATION}

This research is dedicated to all of the children and families currently or formerly involved with the family regulation system. This research would not have been possible without the tireless support of many of our friends, family, and colleagues. A special thanks to Dr. Ellen Lukens, who pushed this team to be what it is, to KLS, without whom none of this would be possible, and to all of the people who volunteered their time to share with us their experiences with the family regulation system: JW, MGO, KS, ALD, NM, and DK. To our partners and loved ones who put up with our late nights and grammatical questions, thank you. To our editors, Caitlin and Sarah, we would not be here today without you. And, to Joyce McMillian, whose work continues to be a source of inspiration.

For further education about the impact of mandated reporting on families or to get involved in the movement to end the family regulation system, we urge you to check out the following: Movement for Family Power, JMacForFamilies, upEND, and Ancient Song Doula Services.

\section{REFERENCES}

A. (Ed.). (n.d.). Abuse/Neglect Investigations by Community District, 20142017. https://wwwl.nyc.gov/assets/acs/pdf/data-analysis/2018/ AbuseNeglectInvestByCommDistrictYrs2014To2017.pdf

Adam, E. K., \& Chase-Lansdale, P. L. (2002). Home sweet home(s): Parental separations, residential moves, and adjustment problems in low-income adolescent girls. Developmental psychology, 38(5), 792-805. doi:10.1037/0012-1649.38.5.792

Anter, A. (2019). The modern state and its monopoly on violence. The Oxford Handbook of Max Weber, 225-236. https://doi.org/10.1093/oxfordhb/9780190679545.013.13

Billingsley, A., \& Giovannoni, J. M. (1972). Children of the storm: Black children and American child welfare. Harcourt Brace Jovanivich.

Brown, A. (2020, October 21). Orphan Trains. Social Welfare History Project. https:// socialwelfare.library.vcu.edu/programs/child-welfarechild-labor/orphan-trains/

Bush, G. (n.d.). Anti-blackness. Antiracist Praxis, American University Washington. https://subjectguides.library.american.edu/c.php?g=1025915\&p=7749761

Child Welfare Information Gateway. (2019). About CAPTA: A legislative history. U.S. Department of Health and Human Services, Children's Bureau. https://www. childwelfare.gov/pubs/factsheets/about/

Connell, C. M., Bergeron, N., Katz, K. H., Saunders, L., \& Tebes, J. K. (2007). Re-referral to child protective services: The influence of child, family, and case characteristics on risk status. Child Abuse \& Neglect, 31(5), 573-588. https://doi. org/10.1016/j.chiabu.2006.12.004

Deisz, R., Doueck, H. J., George, N., \& Levine, M. (1996). Reasonable cause: A qualitative study of mandated reporting. Child Abuse \& Neglect, 20(4), 275-287. https://www.sciencedirect.com/science/article/pii/0145213496000099

Depanfilis, D., \& Zuravin, S. J. (2002). The effect of services on the recurrence of child maltreatment. Child Abuse \& Neglect, 26(2), 187-205. https://doi.org/10.1016/ s0145-2134(01)00316-7 
Desmond, M. (2019, August 14). American capitalism is brutal. You can trace that to the plantation. The New York Times. https://www.nytimes.com/ interactive/2019/08/14/magazine/slavery-capitalism.html

Dettlaff, A. J., Rivaux, S. R., Baumann, D. J., Fluke, J. D., Rycraft, J. R., \& James, J. (2011). Disentangling substantiation: The influence of race, income, and risk on the substantiation decision in child welfare. Children and Youth Services Review, 33, 1630-1637. doi:10.1016/j.childyouth.2011.04.005

Dettlaff, A. J., Weber, K., Pendleton, M., Boyd, R., Bettencourt, B., \& Burton, L. (2020). It is not a broken system, it is a system that needs to be broken: The upEND movement to abolish the child welfare system. Journal of Public Child Welfare, 14(5), 500-517. https://www.tandfonline.com/doi/abs/10.1080/15548732.2020.1814542

DeVernay, A. (Director). (2016). 13th [Film]. Netflix.

Feng, J.Y., Chen, Y.W., Fetzer, S., Feng, M.C., \& Lin, G.L. (2012). Ethical and legal challenges of mandated child abuse reporters. Children and Youth Services Review, 34(1), 276-280. https://doi.org/10.1016/j.childyouth.2011.10.026

Fluke, J. D., Yuan, Y. T., Hedderson, J., \& Curtis, P. A. (2003). Disproportionate representation of race and ethnicity in child maltreatment: Investigation and victimization. Children and Youth Services Review, 25, 359-373. doi:10.1016/S0190-7409(03)00026-4

Frequently Asked Questions. UpEND. https://upendmovement.org/wp-content/ uploads/2020/10/upEND-EXTERNAL-FAQ.pdf

Hanks, A., Solomon, D., \& Weller, C. (2018, February 21). Systemic inequality: How America's structural racism helped create the Black-White wealth gap. Center for American Progress. https://www.americanprogress.org/issues/race/ reports/2018/02/21/447051/systematic-inequality/

Harris, M. S., \& Hackett, W. (2008). Decision points in child welfare: An action research model to address disproportionality. Children and Youth Services Review, 30(2), 199-215. doi:10.1016/j.childyouth.2007.09.006

Hernández, P., Almeida, R. and Dolan-Del Vecchio, K. (2005). Critical consciousness, accountability, and empowerment: Key processes for helping families heal. Family Process, 44, 105-119. https://doi-org.ezproxy.cul.columbia.edu/10.1111/j.15455300.2005.00045.x

Hlavinka, E. (2021, March 12). Racial disparity seen in child abuse reporting. MedPage Today. https://www.medpagetoday.com/meetingcoverage/aap/88958

Hope, E. C., Hoggard, L. S., \& Thomas, A. (2015). Emerging into adulthood in the face of racial discrimination: Physiological, psychological, and sociopolitical consequences for African American youth. Translational Issues in Psychological Science, 1, 342-351. https://psycnet.apa.org/doiLanding?doi=10.1037\%2Ftps000004

Howard, K., Martin, A., Berlin, L. J., \& Brooks-Gunn, J. (2011). Early mother-child separation, parenting, and child well-being in early head start families. Attachment and Human Development, 13, 5-26. doi:10.1080/14616734.2010.488119
Huggins-Hoyt, K.Y., Briggs, H. E., Mowbray, O., \& Allen, J. L. (2019). Privatization, racial disproportionality and disparity in child welfare: Outcomes for foster children of color. Children and Youth Services Review, 99, 125-131. doi:10.1016/j. childyouth.2019.01.041

Joyce, K. (2019, February 25). The crime of parenting while poor. New Republic. Retrieved November 08, 2020, from https://newrepublic.com/article/153062/ crime-parenting-poor-new-york-city-child-welfare-agency-reform

Kalichman, S. C. (1993). Chapters 1, 2, 3, 4, 9. In Mandated reporting of suspected child abuse: ethics, law, \& policy (pp. 11-194). Essay, American Psychological Association.

Kempe, C. H. The Battered Child Syndrome. (1985). https://www.kempe.org/wpcontent/uploads/2015/01/The_Battered_Child_Syndrome.pdf

Kempe, G. H., Silverman, F. N., Steele, B. F., Droegemueller, W., Silver, H.K. (1962). The Battered-Child Syndrome. JAMA 181(1), 17-24. doi:10.1001/ jama.1962.03050270019004

Ketteringham, E. (2019, May 8). Families torn apart over pot: As N.Y. moves to legalize marijuana, it must fix agonizing disparities that take children away from black and brown mothers and fathers. NY Daily News. https://www.nydailynews.com/opinion/ ny-oped-families-ripped-apart-over-pot-20190508-qtrnmuyztzfr7let4vxjxga7zm-story. html

Khan, Y. (2019, April 17). Family separations in our midst | WNYC | New York Public Radio, Podcasts, Live Streaming Radio, News. WNYG. https://www.wnyc.org/story/ child-removals-emergency-powers/

KIDS Count. (2020). Black children continue to be disproportionately represented in foster care. https://datacenter.kidscount.org/

Krase, K. S. (2015). Child maltreatment reporting by educational personnel: Implications for racial disproportionality in the child welfare system. Children \& Schools, 37 , 89-99. doi:10.1093/cs/cdv005

Krase, K. S., \& De-Long-Hamilton, T. A. (2015). Comparing reports of suspected child maltreatment in states with and without Universal Mandated Reporting. Children and Youth Services Review, 50, 96-100. https://doi.org/10.1016/j. childyouth.2015.01.015

Levi, B. H., \& Crowell, K. (2011). Child abuse experts disagree about the threshold for mandated reporting. Clinical Pediatrics, 50(4), 321-329. https://doi. org/10.1177/000992281038917

Mandatory reporting study. (2020). The Marshall Project. https://www. themarshallproject.org/documents/6891700-Mandatory-reporting-study

McTavish, J. R., Kimber, M., Devries, K., Colombini, M., MacGregor, J. C. D., Wathen, C. N., Agarwal, A., \& MacMillan, H. L. (2017). Mandated reporters' experiences with reporting child maltreatment: A meta-synthesis of qualitative studies. BMJ Open, 7(10), 1-15. doi:10.1136/bmjopen-2016-013942 
Melton, G. B. (2005). Mandated reporting: a policy without reason. Child Abuse \& Neglect, 29(1), 9-18. https://doi.org/10.1016/j.chiabu.2004.05.005

Miller, M. (2008). Racial disproportionality in Washington State's child welfare system. Washington State Institute for Public Policy.

National Child Abuse Statistics from NCA. (2020, August 18). https://www. nationalchildrensalliance.org/media-room/national-statistics-on-child-abuse/

National Council of Juvenile and Family Court Judges (NGJFGJ). (2017).

Disproportionality rates for children in foster care: Fiscal year 2015. https://www. ncjfcj.org/wp-content/uploads/2017/09/NCJFGJ-Disproportionality-TAB-2015_0. pdf

New York State, Office of Children and Family Services. Child Protective Services, Family Assessment Response. (n.d). Web. Accessed 11/8/2020. Retrieved from: https://ocfs.ny.gov/main/publications/Pub1159.pdf

Okie, S. (2009, January 27). The epidemic that wasn’t. New York Times. https:// www.nytimes.com/2009/01/27/health/27coca.html

Orphan Train. (2020, October 29). https://en.wikipedia.org/wiki/Orphan_Train

Oversight-Racial Disparities in the Child Welfare System, New York City Council Committee on General Welfare. (2020). (David A. Hansell). https://wwwl .nyc.gov/ assets/acs/pdf/testimony/2020/GWCommitteeHearing.pdf

Putnam-Hornstein, E., Needell, B., King, B., \& Johnson-Motoyama, M. (2013). Racial and ethnic disparities: A population-based examination of risk factors for involvement with child protective services. Child Abuse \& Neglect, 37, 33-46. doi:10.1016/j. chiabu.2012.08.005

Rivaux, S. L., James, J., Wittenstrom, K., Baumann, D., Sheets, J., Henry, J., \& Jeffries, V. (2008). The intersection of race, poverty, and risk: Understanding the decision to provide services to clients and to remove children. Child Welfare, 87, 151-168.

Roberts, D. (2002). Shattered bonds: The color of child welfare. Civitas.

Roberts, D. (2008). The racial geography of child welfare: Toward a new research paradigm. Child Welfare, 87(2), 125-150.

Roberts, D. (2020, June 16). Abolishing policing also means abolishing family regulation. The Imprint. https://imprintnews.org/child-welfare-2/abolishing-policing-alsomeans-abolishing-family-regulation/44480

Sangoi, L. (2020). "How the foster system has become ground zero for the U.S. drug war." Movement for Family Power, NYU Family Defense Clinic, and The Drug Policy Alliance.

Since 1854 Forestdale has helped children and families grow together. (n.d.). Forestdale Inc. History. https://www.forestdaleinc.org/history

Sterilization and Social Justice Lab. (n.d.). Sterilization and Social Justice Lab. Home. https://www.ssjlab.org/
Sullivan, L., \& Walters, A. (2011, October 25). Incentives and cultural bias fuel foster system. NPR. https://www.npr.org/2011/10/25/141662357/incentives-andcultural-bias-fuel-foster-system

United States Department of Health and Human Services, Administration on Children, Youth and Families. (2012). Child maltreatment. U.S. Government Printing Office.

Wexler, R. (2019, January 11). Decades after media, child welfare got "crack babies" wrong, damage to women of color lives on. Youth Today. https://youthtoday. org/2019/01/decades-after-media-child-welfare-got-crack-babies-wrong-damage-towomen-of-color-lives-on/

G INGUANTA (they/them) is an MSW Candidate expecting to Graduate from the Columbia School of Social Work this Spring 2021. G is an AGPP (Advanced Generalist Practice and Programming) student who focuses on Contemporary Social Issues. While at CSSW, G served at Forestdale Inc as a case planner for the Strong Mothers Program and intern at the Bronx Defenders with Healthy Mothers, Healthy Babies in the Family Defense Practice. $\mathrm{G}$ is interested in the intersection between race, gender and state sanctioned violence, thinking about implementing alternatives to capitalism imperialism and dreaming of/making a world where people are truly free.

CATHARINE SCIOLLA (she/her), is a Masters of Science in Social Work candidate at Columbia School of Social Work in Advanced Generalist Practice and Programming concentrating in Contemporary Social Issues. Catharine holds a Bachelor of Art in Psychology from University of Richmond. She is passionate about working with those who have experienced gender-based violence and those who have experienced homelessness. 